\title{
Insights on identifying potential types of guidance for supporting student inquiry when using virtual and remote labs in science
}

\author{
Keysha I. Gamor ${ }^{1}$
}

Accepted: 27 November 2020 / Published online: 11 January 2021

(c) Association for Educational Communications and Technology 2021

\begin{abstract}
This paper is in response to the literature review entitled "Identifying potential types of guidance for supporting student inquiry when using virtual and remote labs in science: a literature review" [Zacharia et al., Educational Technology Research and Development, 63, 257-302 (2015). https://doi.org/10.1007/s11423-015-9370-0] and examines it from a value-add perspective. This literature review illuminates the benefits of leveraging the appropriate types of guidance during the relevant phases of inquiry, a much-needed type of guidance, as it aptly describes how and when to apply the types of guidance for optimal effect. In consideration of some of the weaknesses in the body of literature, as exposed via this literature review, revisiting automated guidance and leveraging any new technological affordances and awareness around adaptive feedback may provide additional insights into how more advanced technologies might contribute to enhanced guidance in computer supported inquiry learning environments.
\end{abstract}

Keywords Guidance · Computer supported learning · Inquiry · Process constraints · Performance dashboard · Prompts · Heuristics $\cdot$ Scaffolds $\cdot$ Direct presentation of information $\cdot$ Automated guidance $\cdot$ Automated tutoring $\cdot$ Adaptive feedback

\section{Introduction}

"Identifying potential types of guidance for supporting student inquiry when using virtual and remote labs in science: a literature review" offers value (impact) to the overall community of educators in two key ways: (1) as a focused, best practices perspective on teaching and learning in an online lab environment and (2) as a timely recommendation for those seeking to use online labs as alternative learning environments as part of a $21 \mathrm{st}$ century learning initiative or in response to other external influences, such as the COVID19 pandemic.

Keysha I. Gamor

kigamor@kg2consulting.com

1 KG2 Consulting, 8300 Greensboro Drive, STE L1-165, McLean, VA 22102, USA 
In this literature review, Zacharia et al. examine the types of guidance needed to support inquiry-based learning in a computer supported inquiry learning (CoSIL) virtual lab used for science education. The authors assert that the nature of inquiry itself is an "active, independent and meaningful process" (p. 258), requiring a special type of support to enhance both the inquiry learning process and the technical subject domain (the science). In general, CoSILs, as constructivist learning environments, have unique characteristics that facilitate learning by challenging students' skills in leveraging the richness and transparency associated with the environment and how information is conveyed (p. 258). Unfortunately, all these goals are rarely met. Yet, the highly independent nature of learning in CoSILs require even more careful planning and attention to constructing meaningful and useful guidance tailored to the learner when and where it is needed most.

\section{Impact}

The value-add/impact of the literature review lies in its structure and how it can be used as a reference tool. The authors classify the types of guidance based on the standard phases of inquiry (the inquiry cycle) and where types of guidance are the most effective in promoting learning during each phase of inquiry. This structure offers readers, not only the what, but also the how, which could help readers prioritize the strategies that they may consider adopting.

The methodology section of the literature review is also organized by the phases of inquiry, which lends itself to being used as a reference tool for anyone designing a CoSIL experience. This is an important contribution because the researchers identify where success is likely to be observed if certain types of guidance are used and where the current body of literature falls short to offer any insights on other types of guidance. Readers, therefore, are empowered to avoid common pitfalls when developing and implementing learning in CoSIL environments. Interestingly, this logic can be applied to most any online learning context where a degree of learner autonomy is part of its design.

\section{Limitations and recommendations}

To further amplify the strengths of the literature review, researchers may consider consulting references, such as Lazonder and Harmsen (2016), Wei et al. (2019), and Rafferty et al. (2013). Research such as these may be of relevance in illuminating how to address some of the limitations that this literature review identified in body of literature.

For instance, Lazonder and Harmsen (2016) is directly relevant to this Zacharia et al. (2015) literature review in that it is a meta-analysis that specifically examined the overall effectiveness of different types of guidance on learning activities, performance success and learning outcomes, among other findings. Future researchers could consult this metaanalysis for insights on the types of guidance and learning activities and could be organized around the inquiry cycle by mapping those activities to where they were placed in the inquiry cycle. Much like the de Jong and Lazonder (2014) taxonomy work, the Lazonder and Harmsen (2016) meta-analysis could provide more insights on the effects of the types of guidance found in the body of literature since this literature review was written.

Wei, J. et al. (2019) and Rafferty et al. (2013), for example, may offer more insights into how to enhance the quality of online interactions and how to facilitate the use of guidance 
through automation, especially useful considerations given the nature of CoSILs as online and, to a large extent, self-directed learning environments. Of particular interest in these studies are student-instructor interactions (Wei, J. et al. 2019, p. 10) and what the researchers refer to as "knowledge integration guidance" (Rafferty et al. 2013, p. 2), as they found this to be as effective as guidance designed by experienced teachers who are trained in the application of knowledge integration. Insights can be gleaned from these articles that may inform how automating this capability increases learner access to this expert level of support and could be explored for ways to make such learning support more widely accessible and learner-centric throughout the entire inquiry process. It could also be useful to compare teacher-generated guidance and the various forms of automated guidance to see if there are some lessons that could be learned about how to enhance automated guidance. A focused examination on adaptive feedback may offer new insights on how technology may impact the quality and utility of the types of guidance studied in this literature review.

In addition, there are many online resources for CoSILs that could be analyzed and recommended as sources of guidance. Perhaps an annotated list of resources that specifically address guidance could make the review an even more useful reference tool.

\section{Conclusion}

Since online learning environments generally require carefully planned instructional support tactics, it stands to reason that an online lab environment would also require at least the same attention. Guidance in an online learning environment is as critical to student learning as observation-based guidance normally experienced in a traditional setting. This research confirms that assumption and offers concrete suggestions on how to apply the knowledge gained from their research and analysis.

Moreover, being able to conduct the process of science inquiry accurately is as critical a learning objective as are those associated with the subject domain addressed in a CoSIL environment. Thus, the roles of teachers and technology are even more magnified, which further highlights the value (impact) and timeliness of this review as a reference tool. It is an exciting time to explore how online instructional strategies (specifically types of guidance) and the technology itself can help to facilitate these goals.

\section{Compliance with ethical standards}

Conflict of interest The author(s) declare no conflict of interest.

Research involved in human or animal rights N/A (No human participants were involved in this writing because this is a response piece for a special issue).

\section{References}

de Jong, T., \& Lazonder, A. W. (2014). The guided discovery principle in multimedia learning. In R. E. Mayer (Ed.), The Cambridge handbook of multimedia learning (2nd ed., pp. 371-390). Cambridge: Cambridge University Press.

Lazonder, A. W., \& Harmsen, R. (2016). Meta-analysis of inquiry-based learning: effects of guidance. Review of Educational Research, 86(3), 681-718. 
Rafferty, A., Gerard, L., Mcelhaney, K., \& Linn, M. (2013). Automating guidance for students' chemistry drawings. CEUR Workshop Proceedings, p. 1009.

Wei, J., et al. (2019). Disciplinary and interdisciplinary. Science Education Research, 1, 14.

Zacharia, Z. C., Manoli, C., Xenofontos, N., et al. (2015). Identifying potential types of guidance for supporting student inquiry when using virtual and remote labs in science: a literature review. Educational Technology Research and Development, 63, 257-302. https://doi.org/10.1007/s11423-015-9370-0.

Publisher's Note Springer Nature remains neutral with regard to jurisdictional claims in published maps and institutional affiliations.

Keysha I. Gamor has more than 15 of experience in instructional design, virtual learning environments (VW, VR, AR, MR), teaching (K-12 and higher ed), online and distance learning, adult education, research methodology, learning and development, assessment and evaluation, and corporate, military, and government training. He serves as Managing Partner of KG2 Consulting LLC, a management, technology, and training consulting firm located in McLean, VA. 